\title{
Parasitological Cure of Chagas Disease: Is it Possible? Is it Relevant?
}

\author{
Julio A Urbina \\ Laboratorio de Química Biológica, Centro de Bioquímica y Biofísica, Instituto Venezolano de Invstigaciones \\ Cientificas Apartado 21827, Caracas 1020A, Venezuela
}

Key words: Chagas disease - Trypanosoma cruzi - parasitology

Nearly 90 million people (about a quarter of the Latin American population) live in zones where Chagas disease is endemic while 18-20 million are already infected with is causative agent, Trypanosoma (Schizotrypanum) cruzi. It is estimated that there are currently $>550,000$ new cases and 50,000 deaths associated to this condition every year (Docampo \& Schmuñis 1997). This disease leads to an annual loss of 2.7 millions of disability adjusted years, being the largest parasitic disease burden in the continent and only third on a global scale after malaria and schistosomiasis (World Bank 1993). Chemotherapy of this disease is still very unsatisfactory, being based in nitrofurans (nifurtimox, Bayer; recently discontinued) and nitroimidazoles (benznidazole, Roche) developed empirically three decades ago. These compounds have activity in the acute and short-term (up to a few years) chronic phase (Andrade et al.1996), but is efficacy varies according to the geographical area, probably due to differences in drug susceptibility of different $T$. cruzi strains (Filardi \& Brener 1987); however, they have little or no activity in prevalent, long term chronic form of the disease, which is widely considered an incurable disease (Rassi \& Luquetti 1992, de Castro 1993, Quintas et al.1996, Andrade et al.1996, Croft et al.1997). Furthermore, both drugs have frequent side effects (generally less severe in pediatric patients) including anorexia, vomiting, peripheral neuropathy and allergic dermopathy (Rassi \& Luquetti 1992, de

\footnotetext{
The work carried out at the author's laboratory received financial support from the UNDP/World Bank/World Health Organization Programme for Research and Training in Tropical Diseases (grants 910359, 930161, 970297), the National Research Council of Venezuela (CONICIT, Grant RP-IV-110034) and the Instituto Venezolano de Investigaciones Científicas.

Fax: 58-2-5041093. E-mail: jaurbina@cbb.ivic.ve Received 9 June 1999

Accepted 9 August 1999
}

Castro 1993, Quintas et al.1996, Croft et al.1997). Although great advances have been made in recent years in the control of the vectorial and transfusional transmission of the disease, particularly through the Southern Cone Initiative involving Brazil, Argentina, Paraguay and Uruguay, progress is uneven in other parts of the continent and the problem of the persons already infected remains unsolved.

In this brief review I would like to discuss recent work, involving the joint effort of biochemists, chemists, parasitologists, molecular and cell biologists and immunologists, that have raised the possibility of radical parasitological cure in chronically infected experimental animals and humans thorough rational chemotherapeutic approaches. I would also like to discuss the role of parasites in the pathogenesis of chronic Chagas disease and thus the relevance of parasitological cure in the clinical outcome of this disease. A more extended version of this discussion has been presented elsewhere (Urbina 1999).

\section{PARASITOLOGICAL CURE OF CHAGAS DISEASE: IS IT POSSIBLE?}

Going beyond the empirical approach, a successful rational approximation to chemotherapy of infectious diseases must take in account validation of both the target and the drug candidate.

Target validation (for a through discussion see Sandler \& Smith 1994) should include: (1) demonstration of the essential character of the targeted metabolic step for the pathogenic organism; (2) the possibility of potent and selective inhibition of the pathogen's target, either through the lack of the target enzyme in the host or the existence of sufficient differences between pathogen and hosts homologous enzymes to allow selective activity.

Validation of the drug candidate should include primarily its capacity to penetrate the target organism and pharmacokinetic/pharmacodynamic properties, which depend on the biology of the hostpathogen relationship as well as on the mechanism of action of the drug. These aspects have received very little attention in the context of Chagas dis- 
ease, but in fact they are of decisive importance. Taking in account the intracellular character of $T$. cruzi parasitism, its relatively slow but sustained proliferation in the host tissues and the necessity of patient compliance during prolonged treatments, some pharmacokinetic/pharmacodynamic properties could be delineated for drugs successfully acting on this parasite in vivo: (1) large volumes of distribution (tissue accumulation); (2) long terminal half lives (slow elimination/biotransformation); (3) oral bioavailability.

In the case of currently available nitrofurans and nitroimidazoles, the empirical approach from which these drugs resulted leaves little room for maneuvering in terms of improving their activity and/or decrease their toxicity, according the principles delineated above: we didn't choose the ball game. However, basic studies in the last two decades have helped to illuminate the molecular basis of both their anti-T. cruzi activity and toxicity (Docampo \& Moreno 1986, Docampo 1990). Nifurtimox acts via the reduction of the nitro group to very reactive nitroanion radicals, which in turn react to produce highly toxic reduced oxygen metabolites. T. cruzi has been shown to be deficient in detoxification mechanisms for oxygen metabolites, particular hydrogen peroxide, and is thus more sensitive to oxidative than vertebrate cells (Docampo 1990). Benznidazole seems to act via a different mechanism (reductive stress), which involves covalent modification of macromolecules by nitroreduction intermediates. Further support for the mechanism of action proposed for nitrofurans and nitroimidazoles comes from the recent demonstration that $T$. cruzi cells which over-express superoxide dismutase have increased sensitivity to benznidazole and gentian violet (Temperton et al. 1998). Based on these findings there is a possibility to increase the activity of these compounds (although toxicity will remain a problem) by selectively interfering with the mechanisms of control of the parasite's redox state. This possibility received strong support by the discovery of trypanothione and trypanothione reductase, a unique system present in trypanosomatids, which replace glutathione and glutathione reductase in these cells as the main intracellular thiol-redox system (Fairlamb \& Cerami 1992). Evidence that trypanothione reductase is an essential enzyme in the related organism Leishmania donovani has been presented (Tovar et al. 1998b); disruption of the trypanothione reductase gene or down regulation of its expression in L. donovani and L. major decrease their ability to survive oxidative stress in macrophages (Dumas et al. 1997, Tovar et al. 1998a), but over-expression of this enzyme in $L$. donovani and $T$. cruzi does not alter their in vitro sensitivity to agents that induce oxidative stress such as nifurtimox, nitrofurazone and gentian violet (Kelly et al. 1993). Although there is currently an intense activity in the search for specific trypanothione reductase inhibitors as potential antiT. cruzi drugs (Bond et al. 1999), none have been reported to have significant anti-parasitic activity, neither in vitro nor in vivo.

Hypoxanthine-guanine phosphoribosyl transpherase (HGPRT) is a trypanosomatid enzyme involved in the scavenging of purines from the host, as these parasites are deficient in the de novo biosynthesis pathway of these essential cellular components. Thus HGPRT is a validated biochemical target for these cells (Quintas et al. 1996). Allopurinol is a pyrazolopyrimidine, which has been used for a long time in humans for the treatment of gout, as it is transformed in vertebrates into oxypurinol, a potent inhibitor of xanthine oxidase. In trypanosomatids, which are deficient in xanthine oxidase, the compound acts as a purine analog and is incorporated into nucleic acids through HGPRT, disrupting the synthesis of RNA and proteins (Quintas et al. 1996). The compound was shown to be active in murine models of acute Chagas disease, but marked differences in susceptibilities among T. cruzi strains were also reported (Avila \& Avila 1981, Avila et al. 1981). There have been conflicting reports of the therapeutic efficacy of allopurinol in humans (de Castro 1993), but a multicentric study launched in 1992 in Argentina, Brazil and Bolivia was stopped as it was a patently demonstrated therapeutic failure (Gianella 1994, World Health Organization 1995). The reasons for the lack of in vivo activity include low incorporation of the drug in the vertebrate stages of many $T$. cruzi strains (Avila \& Avila 1981, Avila et al. 1981) and probably inadequate pharmacokinetic properties, to which no attention have been given. Thus, although HGPRT remains as a valid target we clearly need a valid drug for it.

Currently, the most commonly used drugs for the treatment of diseases caused by fungi and yeasts are compounds that interfere with the de novo biosynthesis or function of sterols in the causative organisms (Yamaguchi et al. 1992, Lyr 1995). Sterol biosynthesis inhibitors (SBI) have been found to be particularly useful, as endogenous sterols are essential for survival in these pathogenic organisms; these compounds are in most cases orally active, have broad spectrum of activity and very low toxicity (Ryder \& Mieth 1992, Mercer 1993, Vanden Bossche 1995). T. cruzi has also an absolute requirement of specific endogenous sterols for cell viability and proliferation and is extremely sensitive to sterol biosynthesis inhibitors (SBI) in vitro (Docampo et al. 1981, Beach et al. 1986, Goad et 
al. 1989, Urbina et al. 1988, 1993, 1995, 1996b, Maldonado et al. 1993); thus, the sterol biosynthesis pathway in this organism is a valid chemotherapeutic target (Urbina 1997). Nevertheless, currently available SBI's, such as ketoconazole and itraconazole, have been shown to be unable to eradicate $T$. cruzi from experimentally infected animals or human patients (McCabe 1988, Moreira et al. 1992, Brener et al. 1993), although a recent report from Chile claims a high level $(>50 \%)$ of parasitological cures in chronic patients treated with itraconazole (Apt et al. 1998). We have recently shown that fourth generation triazole derivatives, such as D0870 (Zeneca Pharmaceuticals) and SCH 56592 (Schering-Plough), are capable of inducing very high rates (70-100\%) of parasitological cure in murine models of acute (short term) and chronic (long term) Chagas disease, while currently available drugs such as nifurtimox and ketoconazole had no significant curative activity in the same models (Urbina et al. 1996a, 1998, Urbina 1997, Liendo et al. 1998). These experimental triazoles are the first compounds ever to display curative activity in the chronic phase of the disease. Furthermore, these compounds are active in vivo against $T$. cruzi strains partially or highly resistant to nifurtimox and benznidazole, in both immunocompetent and immunosuppressed hosts (Molina et al. 1997). In agreement with the postulates presented at the beginning of this section, the special in vivo anti-T. cruzi activity of these compounds has been attributed (Urbina et al. 1996a, 1998, Urbina 1997) to both their selective action on their parasite target (cytochrome P-450 dependent sterol C14 demethylase) and their special pharmacokinetic properties, including large volumes of distribution and long terminal half lives in both experimental animals and humans (Clemons et al. 1993, De Wit et al. 1995, Girijavallabhan et al. 1995, Nomeir et al. 1995, Laughlin et al. 1997). Although development of D0870 has recently been discontinued, SCH 56592 remains a logical candidate for clinical trials with chronic Chagas disease patients. Studies with other triazole derivatives with similar characteristics are currently underway.

Recent studies (Urbina et al. 1998) have shown, using a combination of mono- and bi-dimensional high field ${ }^{31} \mathrm{P}$ nuclear magnetic resonance spectroscopy, specific enzymatic and chromatographic assays, ultrastructural and cell fractionation studies, that inorganic pyrophosphate $\left(\mathrm{P}_{2} \mathrm{O}_{7}^{4-} ; \mathrm{PPi}\right)$ is the major high energy phosphate compound in trypanosomatid (T. cruzi, T. brucei, L. mexicana) and apicomplexan parasites (Toxoplasma gondii), being 5-15 times more abundant than ATP. PPi is distributed throughout the cells but is significantly accumulated in acidocalcisomes, specialized acidic vacuoles present in these parasites which contain their largest intracellular $\mathrm{Ca}^{2+}$ pool (Vercesi et al. 1994, Docampo et al. 1995, Moreno \& Zhong 1996, Vercesi \& Docampo 1996, Lu et al. 1997). The abundance of this compound, together with the presence of recently discovered PPi-using enzymes in $T$. cruzi such as a proton-translocating pyrophosphatase in acidocalcisomes (Scott et al. 1998) and pyruvate, phosphate dikinase (Bringaud et al. 1998), suggest that it may fulfill a primary role in the survival of the parasite. Thus PPi-metabolism is a new validated biochemical target in T. cruzi. This was confirmed by the observation that pamidronate, alendronate and risedronate, FDA-approved non-metabolizable pyrophosphate analogs (bisphosphonates) which are currently used in humans for the treatment of bone resorption disorders (Rogers et al. 1997, Licata 1997, Rodan 1998), blocked the activity of acidocalcisomal pyrophosphatase and selectively inhibited the intracellular proliferation of $T$. cruzi amastigotes and $T$. gondii tachyzoites. Furthermore, pamidronate was shown to be able to profoundly suppress the proliferation of T. cruzi in a murine model of acute Chagas disease. Taken together, these results indicate that bisphosphonates could play an important role in the specific chemotherapy of Chagas disease and other infections caused by protozoan parasites.

\section{PARASITOLOGICAL CURE OF CHAGAS DISEASE:} IS IT RELEVANT?

Although the role of $T$. cruzi in the pathology of acute phase of Chagas disease is widely accepted, through direct damage of the host tissues by the parasite or the ensuing inflammatory process (Quintas \& Siqueira-Batista 1996, Brener \& Gazzinelli 1997), the participation of the parasite in the pathogenesis of chronic Chagas disease has been the subject of many debates (Cunha-Neto et al. 1995, Kalil \& Cunha-Neto 1996, Levin 1996). Several studies have strongly implicated autoimmune phenomena as a primary factor leading to the pathological phenomena associated with this phase of the disease, including classic chagasic cardiomyopathy (Cunha-Neto et al. 1995, Kalil \& Cunha-Neto 1996). This point is of particular relevance to the subject of this discussion, as it has been inferred from this interpretation that after the auto-immune response develops, probably as consequence of "molecular mimicry" between parasite antigens and host's cellular components, the parasite presence should not play a pivotal role in the pathogenesis of the disease (Cunha-Neto et al. 1995, Kalil \& Cunha-Neto 1996). Thus, even a successful antiparasitic treatment may not lead to 
an improvement of the clinical outcome of the patients (Cunha-Neto et al. 1995, Kalil \& Cunha-Neto 1996, Bestetti 1996, 1997). In the following, I will summarize the salient points of this debate:

1 - Presence of T. cruzi in inflammatory lesions: one strong support for the hypothesis of an autoimmune origin of Chagas disease pathology is the apparent lack of parasites in the characteristic inflamamtory lesions present in the heart and other organs in chronic Chagasic patients and experimental animals (Cunha-Neto et al. 1995, Kalil \& Cunha-Neto 1996). However, these studies were carried out using light microscopy techniques of limited sensitivity: more recent work using PCRbased methods have consistently associated specific parasite DNA sequences with active inflammatory lesions, both in humans and experimental animals (Jones et al. 1993, Brandariz et al. 1995, 1996). An important recent study demonstrated, using immunohistochemical and PCR methods, the presence of $T$. cruzi in cardiac tissue of most (>90\%) chronic chagasic patients, including those which received specific (benznidazole) treatment.

2 - Role of the immune system in experimental Chagasic cardiomyopathy: despite previous claims to the contrary (Ribeiro dos Santos et al. 1992), Tarleton et al. (Tarleton et al. 1997) have recently shown that heterotopic neonatal heart transplants to syngeneic mice with chronic experimental Chagas disease and severe cardiomyophaty do no elicit autoimmune-type rejection or are targets of inflammatory response from the host (Tarleton et al. 1997). These transplanted hearts survived for over a year, with normal contractile activity and free of parasites as assessed by a PCR method; they were only rejected when directly injected with live parasites, which leads to a dramatic inflammatory response and cessation of contractile activity (Tarleton et al. 1997). The authors concluded that "the presence of parasites in heart tissue is both necessary and sufficient for the induction of tissue damage in Chagas disease" (see also Levin 1996).

3 - Auto-antibodies in experimental and human Chagas disease: although a large number of vertebrate host's tissue components have been show to cross-react with $T$. cruzi antigens, in many cases these "auto-antibodies" have been shown to be heterophilic in nature (Brener \& Gazzinelli 1997) and not related to the pathology of the disease (Kalil $\&$ Cunha-Neto 1996). Moreover, several lines of evidence show that some of the antibodies previously implicated in Chagas disease pathogenesis (Cunha-Neto et al. 1995) could be more a consequence than a cause of tissue lesions (Levin 1996). Antibodies against the parasite's ribosomal $\mathrm{P}$ proteins cross-react with the host's ribosomal $\mathrm{P}$ proteins but also with the cardiac $\beta_{1}$ receptor
(Rosenbaum et al. 1994, Kaplan et al. 1997) and have been implicated in chagasic cardiomyopathy (Rosenbaum et al. 1994); however, it has recently been shown that these antibodies differ from classical auto-antibodies present in diseases such as lupus erythematosus, being specific for the parasite's antigens and having low affinity for the human antigens (Kaplan et al. 1997).

4 - Effect of specific chemotherapy on the evolution of experimental and human Chagas disease: in experimental infections chemotherapy-induced parasite clearance leads to reversion not only of the inflammatory but also of the fibrotic heart lesions (Andrade et al. 1991). Chronic chagasic patients subjected to antiparasitic treatment (benznidazole), although not parasitologically cured, had a marked reduction in the occurrence of electrocardiographic changes and a lower frequency of deterioration of their clinical condition (Viotti et al. 1994).

\section{CONCLUSIONS}

1 - Recent studies have shown that T. cruzi can be eradicated with high efficacy from both acutely and chronically infected experimental animals, through chemotherapeutic intervention aimed at rationally validated biochemical targets and using drugs with appropriate pharmacokinetic/pharmacodynamic properties. This is expected to apply also to human infections.

2 - Current knowledge seems to indicate that eradication of $T$. cruzi from infected human patients and animals may be prerequisite to arrest the evolution of the disease and to avert its irreversible long-term consequences (Andrade et al. 1991, 1996, Viotti et al. 1994, Docampo \& Schmuñis 1997, Kaplan et al. 1997, Andrade \& Zicker 1997, Urbina 1999). Thus, specific chemotherapeutic approaches should play an essential role in the successful clinical outcome of this parasitic disease.

\section{REFERENCES}

Andrade ALS, Zicker F 1997. Should benznidazole be used in chronic Chagas disease? Lancet 349: 653.

Andrade ALS, Zicker F, Oliveira RM, Silva SA, Luquetti A, Travassos LR, Almeida IC, Andrade SS, Andrade JG, Martelli CMT 1996. Randomised trial of efficacy of benznidazole in treatment of early Trypanossoma cruzi infection. Lancet 348: 1407 1413.

Andrade SG, Stocker-Guerret S, Pimentel AS, Grimaud JA 1991. Reversibility of cardiac fibrosis in mice chronically infected with Trypanosoma cruzi, under specific chemotherapy. Mem Inst Oswaldo Cruz 86: 187-200.

Apt W, Aguilera X, Arribada A, Pérez C, Miranda C, Sánchez G, Zulantay I, Cortés P, Rodriguez J, Juri D 1998. Treatment of chronic Chagas disease with itraconazole and allopurinol. Am J Trop Med Hyg 
59: 133-138.

Avila JL, Avila A 1981. Trypanosoma cruzi: effect of allopurinol in the treatment of mice with experimental acute Chagas disease. Exp Parasitol 51: 204-208.

Avila JL, Avila A, Casanova J 1981. Effects of allopurinol on different strains of Trypanosoma cruzi. Am J Trop Med Hyg 39: 769-774.

Beach DH, Goad LJ, Holz Jr GG 1986. Effects of ketoconazole on sterol biosynthesis by Trypanosoma cruzi. Biochem Biophys Res Comm 135: 851-856.

Bestetti RB 1996. Role of parasites in the pathogenesis of Chagas cardiomyopathy. Lancet 347: 913-914.

Bestetti RB 1997. Should benznidazole be used in chronic Chagas disease? Lancet 349: 653.

Bond CS, Zhang Y, Berriman M, Cunningham ML, Fairlamb AH, Hunter WN 1999. Crystal structure of Trypanosoma cruzi trypanothione reductase in complex with trypanothione and the structure-based discovery of new natural product inhibitors. Structure 7: 81-89.

Brandariz S, Schijman A, Vigliano C, Arteman P, Viotti R, Beldjord C, Levin MJ 1995. Detection of parasite DNA in Chagas' heart disease. Lancet 346: 13701371.

Brandariz S, Schijman A, Vigliano C, Viotti R, Levin MJ 1996. Role of parasites in the pathogenesis of Chagas' cardiomyopathy. Lancet 347: 914.

Brener Z, Gazzinelli RT 1997. Immunological control of Trypanosoma cruzi infection and pathogenesis of Chagas disease. Int Arch Allergy Immunol 114: 103-110.

Brener Z, Cançado JR, Galvão LM, da Luz ZMP, Filardi LdS, Pereira MES, Santos LMT, Cançado CB 1993. An experimental and clinical assay with ketoconazole in the treatment of Chagas disease. Mem Inst Oswaldo Cruz 88: 149-153.

Bringaud F, Baltz D, Baltz T 1998. Functional and molecular characterization of a glycoosmal $\mathrm{PP}_{\mathrm{i}}$-dependent enzyme in trypanosmatids: Pyruvate, phosphate dikinase. Proc Natl Acad Sci USA 95: 7963-7968.

Clemons KV, Hanson LH, Stevens DA 1993. Activities of the triazole D0870 in vitro and against murine blastomycosis. Antimicrob Agents Chemother 37: 1177-1179.

Croft SL, Urbina JA, Brun R 1997. Chemotherapy of human leishmaniasis and trypanosomiasis, p. 245257. In G Hide, JC Mottram, GH Coombs \& PH Holmes, Trypanomiasis and Leishmaniasis, CAB International, London.

Cunha-Neto E, Duranti M, Gruber A, Zingales B, De Messias I, Stolf N, Bellotti G, Patarroyo ME, Kalil J 1995. Autoinmunity in Chagas disease cardiopathy: Biological relevance of a cardiac myosin-specific epitope crossreactive to an inmunodominant Trypanosoma cruzi antigen. Proc Natl Acad Sci USA 92: 3541-3545.

de Castro Solange L 1993. The challenge of Chagas disease chemotherapy: an update of drugs assayed against Trypansoma cruzi. Acta Tropica 53: 83-98.

De Wit S, O’Doherty E, Smith RP, Yates R, Clumeck N 1995. Pharmacokinetics of two multiple dosing regimens of D0870 in HIV positive patients: A phase I study. ICAAC Abstracts 35: F97.

Docampo R 1990. Sensitivity of parasites to free radical damage by antiparasitic drugs. Chem-Biol Interactions 73: 1-27.

Docampo R, Moreno SNJ 1986. Free radical metabolism of antiparasitic agents. Federation Proc 45: 2471-2476.

Docampo R, Schmuñis GA 1997. Sterol biosynthesis inhibitors: potential chemotherapeutics against Chagas disease. Parasitol Today 13: 129-130.

Docampo R, Moreno SNJ, Turrens JF, Katzin AM, Gonzales-Cappa SM, Stoppani AOM 1981. Biochemical and ultrastructural alterations produced by miconazole and econazole in Trypanosoma cruzi. Mol Biochem Parasitol 3: 169-180.

Docampo R, Scott DA, Vercesi AE, Moreno, SNJ 1995. Intracellular $\mathrm{Ca}^{2+}$ storage in acidocalcisomes of Trypanosoma cruzi. Biochem J 310: 1005-1012.

Dumas C, Oulette M, Tovar J, Cunningham ML, Fairlamb AH, Tamar S, Olivier M, Papadopoulou B 1997. Disruption of the trypanothione reductase gene in Leishmania decreases its ability to survive oxidative stress in macrophages. EMBO J 16: 25902598.

Fairlamb AH, Cerami A 1992. Metabolism and functions of trypanothione in kinetoplastida. Ann Rev Microbiol 46: 695-729.

Filardi LS, Brener Z 1987. Susceptibility and natural resistance of Trypanosoma cruzi strains to drugs used in Chagas disease. Trans R Soc Trop Med Hyg 81: 755-759.

Gianella A 1994. Alopurinol en la enfermedad de Chagas crónica. Reunião Anual de Pesquisa Aplicada en Doença de Chagas 10: 89.

Girijavallabhan VM, Saksena AK, Lovey RG, Bennet F, Pike RE, Wang H, Pinto P, Liu YT, Patel N, Ganguly AK 1995. SCH 56592, a novel broad spectrum antifungal agent. ICAAC Abstracts 35: F61.

Goad LJ, Berens RL, Marr JJ, Beach DH, Holz Jr GG 1989. The activity of ketoconazole and other azoles against Trypanosoma cruzi: biochemistry and chemotherapeutic action in vitro. Mol Biochem Parasitol 32: 179-190.

Jones EM, Colley DG, Tosies S, Reis Lopes E, VnencakJones CL, McCurley TL 1993. Amplification of a Trypanosoma cruzi DNA sequence from inflamatory lesions in human chagasic cardiomyopathy. Am J Trop Med Hyg 48: 348-357.

Kalil J, Cunha-Neto E 1996. Autoimmunity in Chagas disease cardiomyopathy: fullfilling the criteria at last? Parasitol Today 12: 396-399.

Kaplan D, Ferrari I, Lopez-Bergami P, Mahler E, Levitus G, Chiale P, Hoebeke J, Van Regenmortel MHV, Levin MJ 1997. Antibodies to ribosomal P proteins of Trypanosoma cruzi in Chagas disease possess functional autoreactivity with heart tissue and differ from anti-P autoantibodies in lupus. Proc Natl Acad Sci USA 94: 10301-10306.

Kelly JM, Taylor MC, Smith K, Hunter KJ, Fairlamb, AH 1993. Phenotype of recombinant Leishmania donovani and Trypanosoma cruzi which over-express trypanothione reductase-sensitivity towards 
agents that are thought to induce oxidative stress. European J Bioch 218: 29-37.

Laughlin M, Pai S, Menon S, Nomeir A, Colucci R, Affrime M, Kosoglou T 1997. SCH 56592: rising multiple-dose safety, tolerance, and pharmacokinetic evaluation in healthy volunteers. ICAAC Abstracts 37: A87.

Levin MJ 1996. In chronic Chagas heart disease, don't forget the parasite. Parasitol Today 12: 415-416.

Licata AA 1997. Bisphosphonate therapy. Am J Med Sci 313: 17-22.

LiendoA, Lazardi K, Urbina JA 1998. Antiproliferative effects and mechanism of action of D0870 and its S(-) enantiomer against Trypanosoma cruzi. J Antimicrob Chemother 41: 197-205.

Lu H-G, Zhong L, Chang K-P, Docampo R 1997. Intracellular $\mathrm{Ca}^{2+}$ pool content and signaling and expression of a calcium pump are linked to virulence in Leishmania mexicana amazonensis amastigotes. $J$ Biol Chem 272: 9464-9473.

Lyr H 1995. Modern Selective Fungicides, 2nd ed., Gustav Fisher Verlag, Jena.

Maldonado RA, Molina J, Payares G, Urbina JA 1993. Experimental chemotherapy with combinations of ergosterol biosynthesis inhibitors in murine models of Chagas disease. Antimicrob Agents Chemother 37: 1353-1359.

McCabe RE 1988. Failure of ketoconazole to cure chronic murine Chagas disease. J Infect Dis 158: 1408-1409.

Mercer EI 1993. Inhibitors of sterol biosynthesis and their applications. Prog Lipid Res 32: 357-416.

Molina J, Araujo MSS, Pereira MES, Brener Z, Urbina JA 1997. Activity of the bis-triazole D0870 against drug-resistant Trypanosoma cruzi strains. ICAAC Abstracts 37: B41b.

Moreira AAB, DeSouza HBWT, Amato Neto V, Matsubara L, Pinto PLS, Tolezano JE, Nunes EV, Okumura M 1992. Avaliacão da atividade terapêutica do itraconazol nas infecçoes crônicas, experimental e humana, pelo Trypanosoma cruzi. Rev Inst Med Trop São Paulo 34: 177-180.

Moreno SNJ, Zhong L 1996. Acidocalcisomes in Toxoplasma gondii tachyzoites. Biochem J 313: 655-659.

Nomeir A, Kumari P, Hilbert MJ, Loebenberg D, Cacciapuoti A, Menzel Jr J, Moss Jr E, Hare R, Miller GH, Cayen MN, Lin CC 1995. Comparative pharmacokinetics of a new triazole antifungal agent, $\mathrm{SCH}$ 56592 , in mice, rats, rabbits, dogs and cynomolgus monkeys. ICAAC Abstracts 35: F68.

Quintas LEM, Siqueira-Batista R 1996. Immunologia, p. 53-74. In R Siqueira-Batista, AD Corrêa \& DW Huggins, Molestia de Chagas, Cultura Médica, Rio de Janeiro.

Quintas LEM, de Castro SL, Urbina JA, Borba-Santos JA, Pinto CN, Siqueira-Batista R, Miranda Filho N 1996. Tratamento da doença de Chagas, p. 125-170. In R Siqueira-Batista, AD Corrêa \& DW Higgins (eds), Molestia de Chagas, Cultura Médica, Rio de Janeiro.

Rassi A, Luquetti AO 1992. Therapy of chagas Disease, p. 237-247. In S Wendel, Z Brener, ME
Camargo \& A Rassi, Chagas Disease (American Trypanosomiasis): Its Impact on Transfusion and Clinical Medicine, ISBT, São Paulo.

Ribeiro dos Santos R, Rossi MA, Laus JL, Santana Silva J, Savino W, Mengel J 1992. Anti-CD4 abrogates rejection and reestablishes long-term tolerance to syngeneic newborn hearts grafted in mice chronically infected with Trypanosoma cruzi . J Exp Med 175: 29-39.

Rodan GA 1998. Mechanisms of action of bisphosphonates. Ann Rev Pharmacol Toxicol 38: 375-388.

Rogers MJ, Watts DJ, Russell RGG 1997. Overview of bisphosphonates. Cancer 80: 1652-1660.

Rosenbaum MB, Chiale PA, Schejtman D, Levin MJ, Elizari MV 1994. Antibodies to beta-adrenergic receptors disclosing agonist-like properties in idiopathic dilated cardiomyopathy and Chagas' heart disease. J Cardiovasc Electrophysiol 5: 367-375.

Ryder NS, Mieth H 1992. Allylamine antifungal drugs. Curr Top Med Mycol 4: 158-188.

Sandler M, Smith HJ 1994. Design of Enzyme Inhibitors as Drugs, Vol. 2, Oxford University Press, Oxford, New York.

Scott DA, DeSouza W, Benchimol M, Zhong L, Lu HG, Moreno SNJ, Docampo R 1998. Presence of a plant-like proton-pumping pyrophosphatase in acidocalcisomes of Trypanosoma cruzi.J Biol Chem 273: 22151-22158.

Tarleton RL, Zhang L, Downs MO 1997. “Autoinmune rejection" of neonatal heart transplants in experimental Chagas disease is a parasite-specific response to infected host tissue. Proc Natl Acad Sci USA 94: 3932-3937.

Temperton NJ, Wilkinson SR, Meyer DJ, Kelly JM 1998. Overexpression of superoxide dismutase in Trypanosoma cruzi results in increased sensitivity to the trypanocydal agents gentian violet and benznidazole. Mol Biochem Parasitol 96: 167-176.

Tovar J, Cunningham ML, Smith AC, Croft SL, Fairlamb AH 1998a. Down-regulation of Leishmania donovani trypanothione reductase by heterologous expression of a trans-dominant homologue: effect on parasite intracellular survival. Proc Natl Acad Sci USA 95: 5311-5316.

Tovar J, Wilkinson S, Mottram JC, Fairlamb AH 1998b. Evidence that trypanothione reductase is an essential enzyme in Leishmania by targeted relacement of the tryA gene locus. Mol Microbiol 29: 653-660.

Urbina JA 1997. Lipid biosynthesis pathways as chemotherapeutic targets in kinetoplastid parasites. Parasitol 117: S91-S99.

Urbina JA 1999. Chemotherapy of Chagas disease: the how and the why. J Mol Med 77: 332-338.

Urbina JA, Lazardi K, Aguirre T, Piras MM, Piras R 1988. Antiproliferative synergism of the allylamine SF-86327 and ketoconazole on epimastigotes and amastigotes of Trypanosoma (Schizotrypanum) cruzi. Antimicrob Agents Chemother 32: 1237-1242.

Urbina JA, Lazardi K, Marchan E, Visbal G, Aguirre T, Piras MM, Piras R, Maldonado RA, Payares G, DeSouza W 1993. Mevinolin (lovastatin) potentiates the antiproliferative effects of ketoconazole and 
terbinafine against Trypanosoma (Schizotrypanum) cruzi: in vivo and in vitro studies. Antimicrob Agents Chemother 37: 580-591.

Urbina JA, Moreno B, Vierkotter S, Oldfield E, Moreno SNJ, Bailey BN, Yan W, Scott DA, Docampo R 1999. Pyrophosphate is the most abundant high-energy phosphate compound in trypanosmatid and apicomplexan parasites and non-metabolizable analogs inhibit their proliferation in vitro and in vivo. Mem Inst Oswaldo Cruz 93 (Suppl. II): 72.

Urbina JA, Payares G, Molina J, Sanoja C, Liendo A, Lazardi K, Piras MM, Piras R, Perez N, Wincker P, Ryley JF 1996a. Cure of short- and long-term experimental Chagas disease using D0870. Science 273: 969-971.

Urbina JA, Payares G, Contreras LM, Liendo A, Sanoja C, Molina J, Piras MM, Piras R, Perez N, Wincker P, Loebenberg D 1998. Antiproliferative effects and mechanism of action of SCH 56592 against Trypanosoma (Schizotrypanum) cruzi: in vitro and in vivo studies. Antimicrob Agents Chemother 42: 17711777.

Urbina JA, Vivas J, Visbal G, Contreras LM 1995. Modification of the sterol composition of Trypanosoma (Schizotrypanum) cruzi epimastigotes by $\Delta^{24(25)}$ sterol methyl transferase inhibitors and their combinations with ketoconazole. Mol Biochem Parasitol 73: 199-210.
Urbina JA, Vivas J, Lazardi K, Molina J, Payares G, Piras MM, Piras R 1996b. Antiproliferative effects of $\Delta^{24(25)}$ sterol methyl transferase inhibitors on Trypanosoma (Schizotrypanum) cruzi: in vitro and in vivo studies. Chemotherapy 42: 294-307.

Vanden Bossche H 1995. Chemotherapy of human fungal infections, p. 431-484. In H Lyr, Modern Selective Fungicides. Properties, Applications, Mechanism of Action, Gustav Fisher Verlag, Jena.

Vercesi AE, Docampo R 1996. Sodium-proton exchange stimulates $\mathrm{Ca}^{2+}$ release from acidocalcisomes of Trypanosoma brucei. Biochem J 315: 265-270.

Vercesi AE, Moreno SNJ, Docampo R 1994. $\mathrm{Ca}^{2+} / \mathrm{H}^{+}$ exchange in acidic vacuoles of Trypanosoma brucei. Biochem J 304: 227-233.

Viotti R, Vigliano C, Armenti H, Segura E 1994. Treatment of chronic Chagas disease with benznidazole: clinical and serologic evolution of patients with longterm follow-up. Am Heart J 127: 151-162.

World Bank 1993. World Development Report 1993/ 1994: Investing in Health, Oxford University Press, Oxford.

World Health Organization 1995. Tropical Disease Research, Twelfth Programme Report, p. 129-133. WHO, Geneva.

Yamaguchi H, Kobayashi GS, Takahashi H 1992. Recent Progress in Antifungal Chemotherapy, Marcel Dekker, New York. 